See discussions, stats, and author profiles for this publication at: https://www.researchgate.net/publication/336477655

\title{
The impact of failure and success experience on drug development
}

Article in Journal of Product Innovation Management · October 2019

DOI: $10.1111 /$ jpim.12514

CITATION

1

4 authors:

7. Antonio Garzon-Vico

University College Dublin

10 PUBLICATIONS 132 CITATIONS

SEE PROFILE

Patrick Gibbons

University College Dublin

33 PUBLICATIONS 767 CITATIONS

SEE PROFILE
READS

117

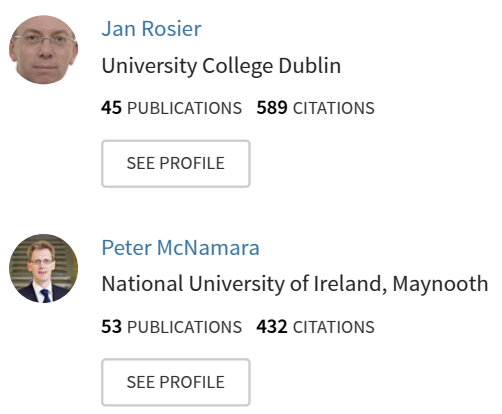

Some of the authors of this publication are also working on these related projects:

research View project

Project Knowledge Management View project 


\title{
THE IMPACT OF FAILURE AND SUCCESS EXPERIENCE ON DRUG DEVELOPMENT
}

\author{
Antonio Garzón Vico, \\ University College Dublin, antonio.garzon@ucd.ie \\ Jan Rosier, \\ University College Dublin, jan.rosier@ucd.ie \\ Patrick Gibbons, \\ University College Dublin, pat.gibbons@ucd.ie \\ Peter Mc Namara, \\ Maynooth University, peter.mcnamara@mu.ie
}

Please note this is an earlier draft (pre-publication) of the paper published in Journal of Product Innovation Management. For the complete final version please see DOI:

10.1111/jpim.12514.

Please cite that version: Garzón Vico, A., Rosier, J., Gibbons, P. and McNamara, P. 2019. The Impact of Failure and Success Experience in Drug Development. Journal of Product Innovation Management, DOI: 10.111/jpim.12514

\begin{abstract}
It is unclear whether the common belief that experience benefits new product development performance is driven by decision-makers allocating more attention to success experience or more attention to failure experience. This paper differentiates between the two aforementioned types of experience in order to explore their separate effects on new product development performance. We find that only late-stage failure experience improves performance, that success experience is more beneficial than late-stage failure experience and that, while others' related failure experience increases the likelihood of failure, others' related success experience decreases it. We conducted our research in the context of drug development in the biotech industry and obtained our data from Pharma Projects.
\end{abstract}

Keywords: Failure, Success, New product development, Others' experience 


\section{Introduction}

On December 2, 2006, Pfizer discovered during phase III trials that one of the most promising projects in its pipeline, torcetrapib - a drug developed to combat heart disease - had in fact increased the risk of death and heart problems. Having already invested US\$800 million in the development of this cholesteryl ester transfer protein (CETP), Pfizer was on the cusp of producing one of the best-selling drugs in history, with expected annual sales of around US\$20 billion. When the adverse discovery was made, Pfizer rapidly stopped development of torcetrapib and immediately suffered a series of drops in its share price (FiercePharma, 2010). The failure of torcetrapib, which had been expected to replace Pfizer's top seller at the time, Lipitor, came as a major shock for the pharmaceutical giant. The event also had an instantaneous effect on other pharmaceutical companies with similar CETP projects in development. Several companies, such as AstraZeneca, followed Pfizer and withdrew their CETP projects. Others, such as Roche and Merck, reacted to Pfizer's failure by improving their own CETP programs. Merck, for example, set about understanding basic CETP biology and slowed down its development plans. Even months after Pfizer's failure, the positive effects could be seen in Merck's own recently developed drug, which showed no increase in blood pressure (Economist, 2006). For Pfizer, the failure was not able to benefit other drugs in its development pipeline, since it did not have any other CETP developments planned. Instead, the company attempted to regroup by taking drastic cost-cutting measures and through the strategic acquisition of smaller firms.

In industries with high levels of uncertainty, such as the biotech industry, more often than not managers must face situations similar to that of torcetrapib. In fact, research shows that, in the biotech industry, $85 \%$ of all projects entering phase I development fail (Hay, Thomas, Craighead, Economides, \& Rosenthal, 2014). New product development (NPD) failure is also widespread in other industries, with rates never dropping below 35\% (Castellion \& Markham, 2013). With such high rates of NPD failure, and the threat they represent for a firm's survival, understanding the impact they have on future NPDs has become a central issue for both practitioners (Barczak, 2014; Collins, 2015) and scholars (Hu, McNamara, \& Piaskowska, 2016; Markovitch, Steckel, Michaut, Philip, \& Tracy, 2015; Shepherd, Haynie, \& Patzelt, 2013). 
Scholars have long held the belief that organizations primarily adapt their behavior from a problemistic search arising from the experience of failure (Cyert \& March, 1963; Madsen \& Desai, 2010; March \& Shapira, 1992). According to the attention-based view (ABV), this is due to the fact that firms' decision-makers are more likely to be aspiration-oriented (Greve, 2003). As such, low performance events, including failures, attract a firm's attention, which in turn leads to a search for new knowledge (Gavetti, Greve, Levinthal, \& Ocasio, 2012). Some scholars argue that we cannot fully understand the implications of failure for the organization without first studying failure in conjunction with success (KC, Staats, \& Gino, 2013; Madsen \& Desai, 2010). On the one hand, a number of studies have found evidence that failure attracts more attention than success and is therefore more beneficial for the performance of organizations (Cannon \& Edmondson, 2001; Madsen \& Desai, 2010). On the other hand, some have found that extracting value from failure is not always straightforward and, under certain circumstances, non-problemistic searches arising from success can even lead to improved performance (Deichmann \& Ende, 2013). Given these contradictory findings, generalizing whether organizations benefit more from failure than from success, or vice versa, is not possible without more research dedicated to the topic (Madsen \& Desai, 2010).

As Figure 1 shows, the purpose of this research is to address the aforementioned gap by looking at the different effects that failure and success have on NPD performance. Consequently, we also answer practitioners' calls for more research into the role of failure in NPD (Barczak, 2014) and extend our understanding of the impact that failure and success have on the performance of future projects in two related directions. First, our study expands our insight into the ways that failure experience affects future NPD performance by showing that it is also important to differentiate among different salience of failure. Based on this, our study shows that the salience of failure, be it early-stage (phase I), medium-stage (phase II) or late-stage (phase III) in our context of clinical trials, affects decision-makers' attention differently and is therefore relevant for understanding its performance. Second, we attempt to determine whether a firm's performance is affected differently depending on whether the decision-maker gives more attention to failure or success. (Madsen \& Desai, 2010). Third, as the torcetrapib example shows, organizations pay attention and can also benefit from the NPD experiences of others (Srinivasan, Haunschild, \& Grewal, 2007; Talay, Calantone, \& Voorhees, 2014). Observing others' failures and successes is crucial for NPD, as organizations have limited resources and time to experiment with all possible outcomes in order to increase their likelihood of success. Therefore, we look at whether others' 
experiences of failure and success have greater impact on future performance than first-hand experience of failure and success.

In order to extend our understanding of the impacts that failure and success have on future project performance, we take NPD in the biotech industry as the context for our research. In this industry, NPD failure can clearly be differentiated into three types of salience according to the stage of development at which they take place (phase I, II and III), which allows additional contributions to be made to the literature by answering calls for more research on the role of different salience of failure and success experiences (Gong, Zhang, \& Xia, 2017). Similar to other studies in the related field, we employ a logit model to explore the impact that failure and success experiences have on the probability of future failure (Madsen \& Desai, 2010)

------ INSERT FIGURE 1 ABOUT HERE -------

\section{Theory And Hypotheses}

According to the ABV of the firm (Ocasio, 1997), firms' behavior - and, by extension, their performance - depends on what their decision-makers pay attention to. The ABV of the firm adopts Herbert Simon's (1947) idea that decision-makers' cognition is limited, meaning they cannot attend to all the stimuli available to them. Given the large amount of information available in a firm's environment and the limits of human cognition, decision-makers must be selective in what they attend to at any one time. The ABV of the firm starts from this assumption of human nature and suggests that firms' decision-makers make decisions using only those experiences that attract their attention.

A major tenet in the ABV of the firm is that individual decision-maker's attention is situated in the context of the firm's activities and procedures. Firms are history-dependent systems and, as such, a firm's experience acts as the basis for the way in which its environment is represented (Daft and Weick, 1984). Consequently, a firm's history affects what its decisionmakers pay attention to, what they do, and thus the future performance of their NPDs (GarzónVico, Gibbons, McNamara, \& Rosier, 2016; Kraaijenbrink, 2012; Paladino, 2007; Wei, Yi, \& Guo, 2014). A firm's experience can affect its performance by directing decision-makers' attention in various ways. For example, a firm's experience can result in decision-makers discriminating 
against irrelevant external information; a process that has the potential to lead to a reduction in project uncertainty (Olivera \& Argote, 1999) or improve a firm's problem-solving capabilities (Grant, 1996; Leonard-Barton, 1992; Nelson \& Winter, 1982). By directing decision-makers' attention, a firm's experience can also facilitate their ability to recognize, assimilate, and exploit new external knowledge (March, 1991) or direct them to the right partners more efficiently (Mayer \& Salomon, 2006).

But not all experiences have the same impact on firms' attention and performance (Argote \& Miron-Spektor, 2011; Darr \& Argote, 1995; Ingram \& Baum, 1997), and this is because different types of experiences have different salience and may not attract decision-makers' attention to the same extent. The salience of an experience is crucial to understanding whether decision-makers will act upon it, as more salient experiences are more likely to attract attention and therefore play a bigger role in a firm's behavior (Gavetti et al., 2012).

A paramount example of salience is failure and success experiences, which largely derive from the fact that decision-makers' attention is performance-oriented: decision-makers are more likely to focus on outcomes relevant to the firm's performance (Greve, 2003). This is why failures such as torcetrapib attract a great deal of attention and determine the firm's subsequent decisions; they suppose a major setback to the performance of the firm in question. It therefore comes as no surprise that numerous scholars have attempted to understand the roles of failure and success in firms' performances in the past (e.g. Baum \& Ingram, 1998; Deichmann \& Ende, 2013; Desai, 2014a; Desai, 2014b; Haunschild \& Sullivan, 2002; KC et al., 2013; Kim \& Miner, 2007; Madsen \& Desai, 2010; Meschi \& Métais, 2015; Shepherd, Patzelt, \& Wolfe, 2011; Su \& McNamara, 2012).

\section{Failure Experience}

NPD failure occurs when initial aspirations regarding the potential of a project are not met by the outcome (Cyert \& March, 1963; Madsen \& Desai, 2010; Shepherd \& Cardon, 2009a; Shepherd, Patzelt, Williams, \& Warnecke, 2014). As a result, firms direct their attention to the failure, and initiate a process of reflection and action with the intention of bringing outcomes and aspirations in line for better performance (Argyris \& Schon, 1996). In order to do achieve this, firms' decision-makers analyze failures to find information that might indicate problems with 
current NPD projects (Hu et al., 2016) and ultimately help them predict future risks (Miner, Kim, Holzinger, \& Haunschild, 1999). Based on this notion, many successful firms admit that part of their success is due to their readiness to react to failures (Gardiner, 2008). This view of how firms react to failures lines up well with Pfizer's actions after torcetrapib's failure. Pfizer investigated the reasons behind the failure, with the intention of predicting possible risks in other existing drug-development projects in its pipeline. This process concluded with different performance-relevant actions, including the termination of other existing projects currently in earlier development stages.

Failure experience can also negatively affect a decision-maker's ability to gather the correct information due to the emotions they cause (Disterer, 2002). Not meeting aspirations regarding a project can trigger and stir negative emotions in organizations (Huy, 2002; Kiefer, 2005; Shepherd et al., 2011), which can in turn lead members of the firm to overestimate the possibility of new failures (Nygren, Isen, Taylor, \& Dulin, 1996), become more inclined to leave the organization (Shepherd et al., 2013), or neglect to analyze the failure (Kiefer, 2005). The importance of emotions lies in the fact they might lead to firm members focusing their attention on explaining the failure away (KC et al., 2013) or determining accountability (Sitkin \& Weingart, 1995). If this occurs, it is likely that time is diverted away from understanding the event itself. Additionally, after a failure, organizations' members might be less inclined to disclose all the relevant information surrounding the failure due to fears of retribution (Mantere, Aula, Schildt, \& Vaara, 2013; Shepherd \& Cardon, 2009b).

\section{Failure Experience Salience}

Although decision-makers in a firm tend to pay attention to, be affected by, and act following failures, not all failures attract the same level of attention or are directed in the same manner. Therefore, we assume that different failure experiences with variations in salience affect firm performance differently. Some scholars argue that failures have different salience based on the cost they represent for the firm and the degree of their rarity, meaning decision-makers' behavior and the future firm's performance are affected differently (Gong et al., 2017; Hayward, 2002; Lampel, Shamsie, \& Shapira, 2009; Madsen \& Desai, 2010). In this respect, the ABV of the firm posits that differences in cost and rarity affect the level of attention that failure experiences receive and, consequently, the impact they will have on future organizational actions (Ocasio, 1997). In 
particular, the more costly and rarer an experience is, the greater attention it will receive, and the greater its impact on future performance will be (Lampel et al., 2009).

In the context of the biotech industry, the salience of a failure, and therefore the attention it receives, depends on the stage of development at which it takes place, since failures at different stages of development carry different cost implications for the firm and are different in how rare they are. As a result, drug-development projects increase their salience, and cost, as they progress through phases I, II and III. According to the latest estimates, out-of-pocket costs are US\$25.3 million for phase I, US\$58.6 million for phase II, and US\$255.4 million for phase III (DiMasi, Grabowski, \& Hansen, 2016). These estimates, together with the cost of preclinical research, can bring the total investment needed for a compound to reach phase III up to US\$2 billion; an amount more difficult to ignore than the smaller loses at phases I and II. Similarly, failures are rarer at phase III than at phases I and II. According to our data, only $14 \%$ of all drugs that enter development fail at phase III, while $38 \%$ fail in phase I and $32 \%$ do so in phase II. Therefore, failures that take place at phase III of development, such as torcetrapib, gain more attention from managers, shareholders, and the public than failures at phase I or II of development due to the higher cost implications and the increased rarity. Furthermore, failures at phase III are more salient, difficult to ignore by organizations, and are more likely to affect future decisions made on ongoing and possible new projects.

As we have already argued, failures have the potential to not only affect firm's performance in a positive sense by attracting the attention of decision-makers and directing future actions, they also can affect performance negatively through bad emotions (Huy, 2002; Kiefer, 2005; Shepherd et al., 2013; Shepherd et al., 2011) and accountability (Sitkin \& Weingart, 1995). It is then natural to assume that the negative impact on performance of negative emotions would increase with the cost implications of the failure, i.e., Phase III failures are more likely to lead to overstating the likelihood of future failure or make it less likely for a firm's members to disclose relevant information regarding the failure than if this occurred during Phases II or I.

Even though we acknowledge accountability and negative emotions as powerful factors affecting how organizations react to failure, we find stronger evidence in the literature to suggest that organizations benefit more from rarer failures with greater cost impact on the firm. Firms are more likely to allocate time and resources to explore the more significant failures among them 
(Kim, Kim, \& Miner, 2009; Madsen \& Desai, 2010). Also, some organizations may turn less salient failures into successes if they do not have major negative consequences (Sitkin \& Pablo, 1992). Similarly, firms may find it easier to ignore failures with less significant cost implications due to the consequences and salience of the latter (Dillon \& Tinsley, 2008). Following the above discussion, we propose the following hypothesis:

Hypothesis 1. First-hand experience of late-stage NPD failure is more likely to reduce future failure than first-hand experience of early-and medium-stage NPD failure.

\section{Success Versus Failure Experience}

According to the ABV of the firm, failure and success experiences affect the attention of decision-makers differently. This is because, contrary to what happens with experience of failure, experience of success can be seen as evidence that organizational knowledge is adequate and that further knowledge development is not necessary (Lant, Milliken, \& Batra, 1992; March \& Shapira, 1992). Although success experience does not lead firms to stop seeking new knowledge, it can lead to excessive trust in existing knowledge (Gino \& Pisano, 2011; Louis \& Sutton, 1991) and inertia (Miller, 1994), in addition to directing a firm's attention towards a "local search" for knowledge - a process that is unchallenged (Lant et al., 1992) - and away from a "non-local search" (Cyert \& March, 1963; Levinthal \& March, 1981). In certain industries, directing your attention towards a local search is not necessarily bad for a firm's performance, as local searches can facilitate the refinement of successful routines and lead to better performance (Muehlfeld, Rao Sahib, \& Van Witteloostuijn, 2012). But in contexts such as the biotech industry, where firms' performances relies on innovation, local searches might not be enough to guarantee an acceptable performance level; decision-makers might be tempted to deviate their attention from relevant nonlocal information (Audia, Locke, \& Smith, 2000; Hayward, Rindova, \& Pollock, 2004) and make flawed inputs (Markovitch et al., 2015), resulting in poor decision-making approaches and an ultimately poorer performance (Audia \& Goncalo, 2007). We find an example of the possible negative impacts of success experiences in a study of the hard-disk drive industry by Audia and Goncalo (2007), in which they discovered that greater success experience led to fewer innovative ideas from employees, who preferred to rely on familiar knowledge instead. 
The idea that experience of success might be less beneficial to future performance than experience of failure in highly innovative industries is supported by Madsen and Desai (2010), who carried out the only direct comparison of these two experiences at the organizational level. Their study focused on the global orbital launch vehicle industry, where success is more common than failure. Their findings support the idea that organizations pay more attention to and benefit more from prior failure than from prior success, resulting in a decrease in the probability of future failure. They argue that failure leads to improvements in performance because it directs an organization's attention towards the search for new knowledge; a process that success, as previously argued, does not necessarily do.

We also find strong evidence in the psychology literature that failures are more likely to attract attention than successes. Studies looking at how individuals react to either a loss or a gain show that, when compared, the former looms larger and has greater salience, and is thus more likely to condition the attention and future decisions of the individual (Kahneman \& Tversky, 2013). This asymmetry between losses and gains has an evolutionary explanation: you are more likely to survive if you treat threats as more urgent (Kahneman, 2011). Therefore, and following the above discussion, we assume that decision-makers will pay more attention to failures than successes in the biotech industry due to the negative implications that such failures have for the firm's survival. As we have already argued, phase III failures in the biotech industry are more likely to attract attention and affect performance than phase I and II failures; as such, we only make a comparison between failure experiences and success experiences found in phase III developments.

Hypothesis 2. First-hand experience of late-stage NPD failure is more likely to reduce future failure than first-hand experience of NPD success.

\section{First-hand Versus Others' Experience of Failure and Success}

Torcetrapib's failure and the consequences it had for other firms represents an example of how organizations can benefit vicariously from others' related failure experiences (e.g. Beckman \& Haunschild, 2002; Bresman, 2013; Haunschild \& Sullivan, 2002; Ingram \& Baum, 1997; Miner \& Haunschild, 1995; Yang, Li, \& Delios, 2015). Research in this area suggests that the likelihood of organizational failure decreases when the number of other organizations experiencing failures increases. This indicates that organizations pay attention to failure when it takes place in their own 
environment, as doing so has the potential to reveal the presence of possible future failures in their own organizations (Baum \& Dahlin, 2007; Haunschild \& Sullivan, 2002; Ingram \& Baum, 1997; Kim \& Miner, 2007). In some industries, the information regarding a failure is made available to the public, making it more likely to attract the attention and condition the behavior of other firms. The orbital launch vehicle industry is an example whereby the disclosure of information following a failure seems to explain why other organizations might benefit from the experience of others (Madsen \& Desai, 2010). Similarly, in the biotech industry, organizations are obliged by law to disclose designs and the results of all clinical studies for treatments within a given period, which in turn facilitates the ability of other firms to inform their decisions from observing others' failures

Despite there being plenty of evidence to suggest that organizations do pay attention to, and benefit from, the experiences of others (Baum \& Dahlin, 2007; Haunschild \& Sullivan, 2002; Ingram \& Baum, 1997; Kim \& Miner, 2007; Scarbrough, Robertson, \& Swan, 2015), it is not yet clear in the literature whether organizations benefit more from their own failures or more from others'. We propose that organizations benefit more from observing others' failures than from their own because, as previously argued, the experience of failing can affect their ability to extract relevant lessons from the experience. Furthermore, the observing firm will not be affected by all the financial and emotional implications of the failure, which, as previously mentioned, can affect the performance of the organization.

Pfizer's failure exemplifies the situation described above. The fact it was Pfizer involved in the failure created a sense of panic, as the firm's current market leader was set to expire five years down the line. Most of the efforts after the failure were concentrated on developing drastic measures that could prevent an immediate catastrophe. One such measure was the immediate task of cutting 10,000 jobs. During the time in which Pfizer was concentrating on these measures, other competitors could sit back and begin the process of analyzing torcetrapib's failure. This explains why, contrary to what happened to Pfizer, the outlook for companies such as AstraZeneca, Roche, and Merck improved at the news of the termination of torcetrapib's development. As argued above, the fact that these firms were not directly involved in the failure gave them the financial and emotional security needed to make better decisions.

Additionally, the fact that AstraZeneca, Merck, and Roche had similar projects to torcetrapib in their pipelines allowed them to review and evaluate the consequences of the torcetrapib failure for their own projects, which were still in the early stages of development. This is in line with findings in the literature that support the idea that organizations pay more attention and benefit more from others' experiences if they are related to their own past and present 
experience (Bresman, 2013; Nesta \& Saviotti, 2005). Additionally, when an organization is familiar with the experience of another company, it will be more likely to employ and use this known experience more appropriately, without having to translate it to an unrelated context (Hora \& Klassen, 2013; Ingram \& Baum, 1997). Based on the above discussion, we propose the following hypothesis:

Hypothesis 3. Others' related experience of late-stage NPD failure is more likely to reduce future NPD failure than first-hand experience of late-stage NPD failure.

Organizations not only pay attention to and make decisions based on others' failures, they also closely follow and benefit from others' successes (Madsen \& Desai, 2010). In a context of shared knowledge bases, observing others' success might prompt an organization to copy the practices of the succeeding organization (Carroll \& Hannan, 1995; Miner et al., 1999). This is why firms that operate in a common domain typically employ similar practices. In the biotech industry, it is common that an initial success in combating a certain illness prompts other competitors to adopt similar approaches.

We previously argued that first-hand success experience can be self-limiting and affect performance negatively, often resulting in firms implementing a local search and becoming overconfident (Audia et al., 2000; Hayward et al., 2004). This is not the case when a firm observes others' successes. It is, in fact, the contrary: watching others' successes might create a sense of urgency in the observing firm, pushing it to imitate as a way of replicating a similar successful outcome and maintain a competitive advantage (Posen, Lee, \& Yi, 2013). Following the above discussion, we propose the following hypothesis:

Hypothesis 4. Others' related experience of NPD success is more likely to reduce future failure than first-hand experience of NPD success.

\section{Methodology}

\section{Research Setting}

The biotech industry offers fertile ground through which to answer our research question. Efficiently responding to new advances and developments is crucial, since companies face 
tremendous pressure to innovate. In the last 10 years, the number of drugs in development has increased by $62 \%$, whilst research and development (R\&D) expenditure has doubled. Although the number of new medicines reaching the market picked up in 2015, annual output has effectively flatlined over the same period; developing new medicines is becoming an increasingly expensive business (the average cost per molecule is anything from US\$75 million to US\$4 billion), and the regulatory context of drug development is also becoming more rigorous (e.g., the Food and Drug Administration is building an active surveillance system called Sentinel to oversee the safety of all medicines on the US market). Virtually all firms in the biotech industry have multiple product candidates in their development pipelines. Given the low probability of a product reaching the market, ranging between $10 \%$ and $15 \%$ (Hay et al., 2014), a critical factor for managers is to allocate R\&D resources wisely. In this context, maximizing the use of first-hand and others' experiences for drug development is of vital importance in the biotech industry, as doing so informs decisions regarding costly project development.

\section{Sample and Data}

We obtained the data with which to conduct our research from Pharma Projects, a database containing information on pharmaceutical and biotech drug-development projects. The source data are based on company questionnaires, and the filings, journals, annual reports, industry conferences, and press releases of the US Securities and Exchange Commission and US Food and Drug Administration. Pharma Projects includes data from more than 600 biotech and biopharmaceutical companies, with detailed profiles showing joint ventures, licensing agreements, and over 29,000 detailed drug profiles, including 217 therapy profiles. The information in the database is regularly updated and includes all historical information on every compound ever recorded.

We focused our search only on those drugs that had a biological origin; these included biological cells, cellular structural components, and macromolecules (including DNA/RNA, peptides, proteins, and structural polysaccharides/lipids) from natural sources. Like similar studies that use data on drug development for their analysis, we believe that focusing on biologic drugs (large molecules) ensures homogeneous sampling and controls for variance that exists within the broader group of pharma/biotech/life sciences products (e.g. Hoang \& Rothaermel, 2005, 2010). We focused only on drugs that were either fully launched or ceased between January 2000 and March 2015, and that had entered clinical trials. It is only when drugs enter clinical trials involving humans that information on failures becomes widely available. Also, it is only when humans are involved in trials that failures have a significant impact on firms, both financially and socially. 
For all projects, an event date (either for full launch or cessation) was identified. This resulted in a total sample of 1,749 drugs, of which $264(15.09 \%)$ were fully launched, and 1,485 $(84.91 \%)$ were ceased during the 15 -year period. A total of 904 organizations participated in the development of the 1,749 drugs as either originators or licensees. Because we wanted to explore the impact of failure and success experiences on future performance and because, in some cases, more than one organization was involved in the development of one drug, we organized our data as unbalanced panel data. We ended up with a total of 2,981 observations for all 904 organizations and 1,749 drugs. Some of the organizations in our sample only took part in a very small number of drug-development projects and were subsequently left out of our fixed-effects analysis. Fixedeffects analysis controls for firm heterogeneity and, as such, does not consider those firms with all drug-development projects as either failures or successes. This subsample, which contained a total of 1,145 observations developed by a total of 79 organizations, was employed to build our model. Nonetheless, we used the full 2,981 observations to construct our variables for others' organizational experiences.

\section{Dependent Variable}

Our dependent variable represents whether a given drug-development project has been fully launched or ceased. All the projects are either clear launches or ceased projects. In the biotech industry, it is widely assumed that drugs that are fully launched are those that have reached the market and have therefore completed all clinical trials successfully and passed the necessary regulatory approvals. We define 'ceased' as those drug-development projects that have been stopped before reaching the market. A drug-development project can either be ceased after phase I, II, or III trials, or at the time of assessment by the regulatory agency. Each phase of development involves a larger number of patients and greater overall costs. In our sample, the reasons for ceasing a project are always scientific, meaning that the results of the clinical trials did not prove the efficacy of the drug in question. Thus, ceased is a dichotomous dummy variable, coded 1 for ceased projects and 0 for fully launched.

\section{Independent Variables}

The variable measuring first-hand early-stage failure experience represents the number of failed projects at phase I of development in which an organization was involved as either an originator or a licensee. The variable measuring first-hand medium-stage failure experience 
represents the number of failed projects at phase II of development in which an organization was involved as either an originator or a licensee. The variable measuring first-hand late-stage failure experience represents the number of failed projects at phase III of development in which an organization was involved as either an originator or a licensee. The first-hand success experience variable is the number of successful prior projects in which an organization was involved as either an originator or a licensee. The variable measuring others' related success experience is the number of fully launched projects in the same therapeutic area as the project in question by other organizations. The variable measuring others' related late-stage failure experience is the number of projects ceased in phase III in the same therapeutic area as the project in question by other organizations.

During the time covered by the sample, several organizations in our sample merged with others or were acquired by others. In these cases, the above experience variables were constructed so as to account for all the prior experience possessed by the merged or acquired organization.

\section{Experience Discount Factor}

Some researchers suggests that the value of experience depreciates over time (Kim \& Miner, 2007; Olivera \& Argote, 1999). Extracting value from distant experience can lead organizations to adopt routines that worked well in the past but that are no longer useful (Levinthal and March, 1993). Because there is often no theoretical basis for a specific functional form of the depreciation of experience, previous researchers have often used a pre-specified model of experience devaluation (Darr \& Argote, 1995; Ingram \& Baum, 1997; Kim \& Miner, 2007; Madsen \& Desai, 2010). In order to account for the depreciation of past experience over time and as a robustness test, we employed a series of arbitrarily selected discount factors by which prior experiences are divided before being added into a cumulative past experience variable. First, we used a discount factor equal to 1, assuming no depreciation in the value of past experience. Second, we set the depreciation factor to the square root of the age of the experience, assuming that experience initially depreciates more slowly than linearly and slows further with time. Third, we used a discount factor equal to the age of the experience, assuming that experience depreciates in linear fashion. Fourth, we set the discount factor equal to the experience age squared, assuming that the value of past experience depreciates faster than linearly at first and then accelerates further with time. We employed the discount that yielded a better fit for the model. 


\section{Control Variables}

Based on prior research in drug-development projects, which shows that the scientific characteristics of the drugs may affect the outcome of the project (Danzon, Nicholson, \& Pereira, 2005; Macher \& Boerner, 2006), we created various variables covering scientific aspects of the drug-development projects. therapeutic area risk measures the percentage of prior failed projects within the therapeutic area of the focal drug at the time of the event. Similarly, the variable biological origin risk measures the percentage of prior failed drug-development projects within the biological origin group of the focal drug at the time of the event. Both of these variables control for the difference of scientific complexity behind each drug-development project. We also controlled for whether the drug-development project targeted a rare disease. Rare diseases are less likely to be the subject of scientific research, i.e., there may be less interest, resources, and political drive behind their development. We employed a dummy variable (rare disease) with 1 indicating those drugs listed as rare diseases by the Genetic and Rare Diseases Association.

Whether a project is conducted solo or in collaboration with other firms can affect support for a project. We created a dummy variable ( $R \& D$ alliance), where 0 denotes a solo project and 1 denotes a project conducted in collaboration with another firm. As a way to control for unobservable year effects, such as the introduction of new technologies in drug development, and for correct truncation, the variable year indicates the year in which the project was initiated. We also controlled for the organization's size, as this may affect its ability to extract value from both failure and success. Following several prior studies that have used R\&D expenditure as a proxy to an organization's size (e.g. Lee \& Chen, 2009), we created the variable $R \& D$ investment, which measures the total amount invested in the years prior to the date of observation. We also controlled for the role that the organization plays in the development of the drug in question. The dummy variable organization's role is coded 1 for companies that are the originator of the compound and 0 for companies that act as licensees. The experience and expertise an organization has in terms of its drug-development project is relevant to its future performance (Macher \& Boerner, 2012). By employing the number of previous drugs developed by the same organization in that particular therapeutic area, we thus created the variable therapeutic area experience to capture the level of expertise held by the organization. We also measured the percentage of total failed projects per organization (percentage failed) to control for the relationship between failed and successful projects. 
In addition, we employed Heckman's selection model to control for the endogeneity of strategic decisions. The decision regarding the future of projects can be determined by unobserved factors that are not available or reflected in the model, so not controlling for them could result in misleading results (Argyres \& Liebeskind, 2002). We employed Heckman's first-stage model to create a selection term that controls for endogeneity in the second-stage analysis (Heckman, 1979). Heckman's first-stage model consists of a multinominal logit model that estimates the probability of a firm choosing to either terminate or keep a project in development. In this model, we included the independent and control variables. This first-stage model returned an adjustment term - an inverse Mills ratio - which was then included in the later model.

\section{Analysis}

Similar to previous studies on failure experience (e. g. Madsen \& Desai, 2010), we used logistic regression analysis to model the likelihood that a drug-development project resulted in failure. This is common for binary-response models, such as ours, where the dependent variable has only two possible values. We included firm-specific fixed effects to control for unobserved heterogeneity (Hosmer Jr, Lemeshow, \& Sturdivant, 2013). The inclusion of organizations' fixed effects was necessary because many characteristics of the firms were unobservable during the period of the study. The fixed-effects regression model takes the form:

$$
\log \left(\frac{P_{j}}{1-P_{j}}\right)=\alpha_{i}+x_{i j}^{\prime} \beta+e_{i j}
$$

where $P j$ is the probability that drug-development project $j$ will fail, and $\alpha_{i}$ is a firm-specific paramenter representing the effect of unobserved firm characteristics. $\beta$ signifies regression coefficients representing the effects of the observed covariates, and $e_{i j}$ independent error terms.

\section{Results}

Table 1 presents descriptive statistics and correlations for the variables included in this study. The experience variables used in this study were depreciated using their best-fitting depreciation value. The different values are reported in brackets below each variable. There are some moderate correlations. The reason for the moderate correlation between $R \& D$ alliance and 
organization's role $(r=0.67)$ is that all those organizations that were the solo developers of a drug (value of 1 for governance) were also the originators (value of 1 for organization's role). There is also a moderate correlation between first-hand late-stage failure experience and $R \& D$ investment $(\mathrm{r}=0.66)$. We ran the analysis without the control variables for $R \& D$ alliance and $R \& D$ investment, and the results followed the same pattern.

\section{----- INSERT TABLE 1 ABOUT HERE ----}

Table 2 reports maximum-likelihood estimates for the fixed-effects logit regression analysis of drug failures. Model 1 contains only control variables that can be used for comparison against the models containing experience variables. In Model 1, we see that the coefficient for calendar year is positive and significant, suggesting that since 2000, the likelihood of failure has increased. This finding is in line with recent studies in the industry showing that the likelihood of failure has increased over the last decade due to regulatory changes (Hay et al., 2014). We also find that, as the percentage of failed drug-development projects increases, the likelihood of future failure decreases. Our results also show that increasing the complexity of the science, both for the therapeutic area and biological origin, increases the likelihood of future failure. Furthermore, Model 1 also shows that more R\&D investment reduces the likelihood of future failure. In particular, a marginal-effects analysis at mean values for all other variables shows that increasing R\&D investment by US\$1 billion would decrease the likelihood of failure by 11 percentage points. The statistical significance of the inverse Mills ratio indicates that unobserved characteristics underlying the decisions made by drug-development firms also influence the likelihood of future failure.

\section{------ INSERT TABLE 2 ABOUT HERE ------}

Models 2 to 6 look at the impact of first-hand early-stage failure experience, first-hand medium-stage failure experience, first-hand late-stage failure experience, and first-hand success experience on the likelihood of drug failure. Hypothesis 1 suggested that the probability of drug failure is lower with first-hand experience of late-stage failure than with first-hand experience of early- and medium-stage failure. In Model 4, the first-hand late-stage failure experience coefficient is negative and significant $(p<.05)$, indicating that the probability of failure decreases as organizations gain experience of late-stage failure. We also conducted a marginal-effects analysis for first-hand late-stage failure experience and present the results in Figure 2. Increasing first-hand late-stage failure experience by one standard deviation, whilst keeping all other variables at mean values, decreases the probability of failure by 45 percentage points. In Models 2 and 3, the coefficients for first-hand early- and medium-stage failure experiences are positive and non- 
significant. These results remain stable when included together in Model 6. These results support Hypothesis 1 and indicate that first-hand late-stage failure experience is more likely to reduce future failure than first-hand experience of early- or medium-stage failure.

\section{----- INSERT FIGURE 2 ABOUT HERE ------}

In Hypothesis 2, we suggested that the probability of drug failure is lower with first-hand experience of late-stage failure than with first-hand experience of success. In Model 5, we find that the first-hand success experience coefficient for the probability of failure rate is negative and significant $(p<.001)$. This finding indicates that failures become less likely as organizations gain experience of success. To determine the net effect of first-hand success experience, we predicted probabilities of project failure against first-hand success experience, with all other variables calculated at their mean value. Figure 3 indicates that an organization's first-hand success experience has a negative impact on the probability of future failure. In particular, our analysis shows that, keeping all other variables at mean values, increasing the first-hand success experience variable by one standard deviation reduces the probability of failure by 48 percentage points. Model 6 includes both first-hand experience variables. In Model 6, we see how the coefficients for first-hand experience of late-stage failure and success remain stable. A Wald test $(p<.001)$ suggests that the first-hand success experience coefficient in Model 6 is significantly more negative than the coefficient for first-hand late-stage failure experience. This is consistent with the argument that success experience is more likely to reduce future failure than first-hand experience of late-stage failure. These findings do not support Hypothesis 2.

\section{------ INSERT FIGURE 3 ABOUT HERE ------}

Hypothesis 3 suggested that the probability of drug failure is lower with others' related experience of late-stage failure than with first-hand experience of late-stage failure. In Model 7 , we can see that the impact of others' related late-stage failure experience on the probability of future failure is positive and significant $(p<.05)$. This indicates that the likelihood of future failure increases as the number of others' related late-stage failure increases. In Model 8, others' related late-stage failure experience and first-hand late-stage failure experience both remain unchanged. We also conducted marginal-effects analysis for others' related late-stage failure experience and present them in Figure 4. Further analysis shows that increasing others' related late-stage failure experience by one standard deviation, whilst keeping all other variables at mean values, increases the probability of failure by 37 percentage points. These results do not support Hypothesis 3 , as the coefficient for first-hand late-stage failure experience is negative whilst the coefficient for others' related late-stage failure experience is positive. 


\section{----- INSERT FIGURE 4 ABOUT HERE}

In Hypothesis 4, we anticipated that others' related experience of success reduces the likelihood of failure more than first-hand experience of success. In Model 9, we can see how others' related success experience is negative and significant $(p<.001)$. This value remains negative although it loses some significance $(p<.01)$ when the others' related success experience variable is included with first-hand success experience in Model 10. We can also appreciate how first-hand success experience becomes non-significant, even though it remains negative, when combined with others' related success experience in Model 8. These results support Hypothesis 4 and suggest that others' related success experience is more likely to reduce future failure than firsthand success experience. We also conducted a marginal-effects analysis for others' related success experience and present the results in Figure 5. Increasing others' related success experience by one standard deviation, whilst keeping all other variables at mean values, decreases the probability of failure by 55 percentage points.

\section{------ INSERT FIGURE 5 ABOUT HERE ------}

\section{Robustness Tests}

In addition to the main analyses reported above, we conducted supplementary analyses to assess whether our results were robust. First, whilst the use of fixed-effects models is consistent with previous studies on failure (Madsen \& Desai, 2010), there are other ways to model our data. Specifically, we used a probit random-effects specification to address the non-independence of observations within organizations (Wry, Lounsbury, \& Jenni, 2014). A random-effects specification divides the residual of each observation into organization-specific and other components to allow for organization-level changes through time. The advantage of randomeffects modeling is that it looks at the increase in the odds of failure averaged over all the organizations in the population and not just in the increase in the odds of failure in the organization the drug belongs to. Because the focus in random-effects modeling is the whole population, these analyses included firms that had only successes or failures and that were left out of the fixedeffects analysis. We used the 'xtprobit' command in STATA 12, and present the results in Table 3. The pattern of results was similar to the fixed-effects model with no changes in the signs of the experience variables.

We also conducted analyses using a theoretical rationale based on our interactions with practitioners in the industry. We assumed that phase I failure experiences, due to their smaller cost implications, depreciate the fastest; therefore, we used the square of their ages. For phase II failure 
experiences, we used an age discount to represent a slower depreciation of knowledge to that of phase I failure experiences. Lastly, we assumed that, due to the magnitude involved, both firsthand and others' phase III failure experiences would depreciate even more slowly than those experiences of phase II. Therefore, we employed a depreciation factor of the square root of their ages. The results yielded the same support to our hypotheses as the main models. We also followed other prior studies when using the same discount factor for different types and employed the age of the experience as a discount (Kim et al., 2009; Meschi \& Métais, 2013). The direction of the predictions was the same as those in the main analysis.

One of the concerns when developing the ideas in this study was whether the explanatory variables employed added extra explanatory power. One of the aims of the research presented here was to suggest that breaking down first-hand total failure experience into early-, medium-, and late-stage phases is of interest when explaining drug failure. In order to test whether early-, medium-, and late-stage failure experience added any value to the analysis, we reanalyzed the data with a total first-hand failure experience. The resulting model was significant, but the models that disaggregated total failure experience into first-hand early-stage, medium-stage, and late-stage failure experience yielded a better fit.

\section{Discussion}

We examined whether experiences of NPD failure and success shape the outcome of a firm's subsequent NPD. In particular, we looked at failure experiences with different salience, focusing on whether they took place within or outside the firm. Using the ABV of the firm, we considered different mechanisms to explain whether a type of experience - failure or success - is more likely to attract the attention of decision-makers, and whether this affects the performance of future NPD. Our work contributes to the ABV-of-the-firm literature in several ways.

First, this study complements the ABV of the firm by being the first to show that NPD failures attract the attention of decision-makers differently, depending on the stage of development at which they take place. In particular, our work shows that failure attracts firms' attention and improves performance only if the failure is substantially salient in terms of its financial implications and rarity. We argued that when a failure has major financial consequences and is rare, it will get more organizational attention and, therefore, be more likely to affect decisions regarding ongoing and future NPD. This goes some way in explaining our findings. Early and medium failures in the biotech industry have considerably smaller financial consequences and are 
more frequent than late-stage failures. Indeed, our results are consistent with the notion that organizations are less likely to benefit from failures that are not rare and/or have no major financial consequences relative to others' failure events. We do not argue that the financial consequences of small- and medium-stage failures in the biotech industry are not considerable, only that in situations in which organizational attention is limited, it will be those rarer events with greater impact that become managers' primary focus of attention. Our findings extend the idea that more salient failures are more difficult to ignore by firms and are, consequently, more likely to affect any future decisions made (Madsen \& Desai, 2010).

Second, our findings run counter to theories suggesting that accountability and negative emotions after salient failures negatively affect future performance. For example, our results are at odds with the small-losses hypothesis in the ABV-of-the-firm literature, which argues that, after salient failures, organizations are more prone to dedicating a greater deal of their attention to determining accountability, rather than understanding the event and improving future performance (Gong et al., 2017; Hayward, 2002). On the contrary, our results suggest that, in the biotech industry, firms dedicating some of their attention to accountability are still able to pay attention to understanding the event. Similarly, our findings are also at odds with studies claiming that more salient failures are associated with greater negative emotions, and thus lead to a decrease in future performance (Mantere, Aula, Schildt, \& Vaara, 2013; Shepherd \& Cardon, 2009b). One reason that might explain why late-stage failure experience does not lead to accountability and/or emotions affecting the performance of future NPD is that, in the biotech industry, there exists a stronger normalization of failure, which might reduce the need to blame others, and see a reduced intensity of negative effects (Shepherd et al., 2011). We do not interpret this finding as evidence that negative emotions or accountability do not play a role in future actions that might affect the future of forthcoming NPD, but it does suggest that the salience of late-stage failures plays a bigger role in pushing the firm towards scrutinizing and extracting information relevant to the event in question.

Third, our results challenge the ABV-of-the-firm assumption that organizations pay more attention to, and benefit more from, knowledge searches sparked by prior failure (Cyert \& March, 1963; Lant et al., 1992; Madsen \& Desai, 2010; March \& Shapira, 1992). Contrary to our findings, Madsen and Desai (2010) show that failure attracts the attention of decision-makers and promotes improvement more so than success; however, their study is in the orbital launch vehicle industry, where successes are the norm. In the biotech industry, successes are rare, with only $15 \%$ of all drugs successfully reaching the market. This difference in the rate of success in both industries 
might explain the fact that, in our study, success attracts more attention and leads to better performance. In fact, our findings support other prior studies claiming that rare successes are seen by managers as rich examples to follow and a way to excel during new projects (Deichmann \& Ende, 2013; KC et al., 2013; Lampel et al., 2009). Furthermore, in the context of the biotech industry, successes not only indicate the success of a particular drug but also the success of a certain strategy to combat a disease. Therefore, in an industry in which successes are rare, an organization may be led to believe that their strategy -scanning the environment for new knowledge and translating it into a product - is adequate. We therefore posit that our results are more likely to be generalizable to other NPD industries that share similar rates of success, and to early-, medium-, and late-stage failures within the biotech industry. This is an important contribution because, as our results show, whether organizations decide to pay more attention to failure or to success depends on the characteristics of the industry. Comparing results across industries helps us draw some conclusions on the roles of failure and success experiences on NPD performance.

Fourth, this work addresses other significant questions regarding the boundary conditions of failure and success experiences. In particular, our results show that an increase in others' related late-stage failure experience results in an increase in the likelihood of future failure in the organization, which indicates that the attention that others' related failures attracts does not lead to an improvement in performance. Our results are in contrast to certain scholastic claims that others' failures help improve the performance of other observing organizations (Baum \& Dahlin, 2007; Madsen \& Desai, 2010). We interpret these findings as indicating that the related late-stage failures of others do in fact attract the attention of decision-makers, but not because they are interested in extracting information to improve the prospects of their own similar drugdevelopment projects. Rather, such decision-makers, particularly those in the biotech industry, are more interested in the efficacy of a certain strategy in combating a certain disease. In other words, a drug failure might push observing firms to examine the evidence surrounding their own similar projects; a process that often results in the project being terminated. An example is bapineuzumab, a drug to combat Alzheimer's disease, that failed at phase III in 2012. This late-stage failure led to a sense of panic in observing firms with similar projects, resulting in many of them being terminated.

Fifth, our study also finds builds on the ABV of the firm by expanding our knowledge in terms of the way that firms react to other's related successes in the industry. In particular, this study supports the claim that others' related success experience has a greater impact on future 
performance than first-hand success experience. This results in other observing organizations directing their attention to the successful strategy with a view to replicating its success. Moreover, a proven strategy to combat a certain disease will probably count on increased backing by other observing organizations. Despite first-hand success experience having a positive impact on the performance of future drug developments, our results show that the impact of others' related success experience is greater in terms of its influence. One possible reason for this might be that certain successes in the biotech industry has seen some decision-makers becoming overconfident (Gino \& Pisano, 2011; Louis \& Sutton, 1991). As argued previously, the financial implications of success might remove some of the urgency in looking for new innovative drugs, resulting in organizations becoming less inclined, or able, to reduce the probability of future failure. The fact that observing organizations do not reap the financial rewards from the success, and are consequently less susceptible to overconfidence, might explain how they benefit more from the experience.

\section{Implications for Practice}

The results of this study have several implications for practice. First, as highlighted by Madsen and Desai (2010), how organizations deal with failure explains inter-organizational variation in performance. These authors suggest that managers should acknowledge failures in order to recognize the central role they play in organizational performance. According to their findings, organizations' leaders should not ignore failures; rather, they should treat them as invaluable opportunities. Our findings expand upon this assertion, suggesting that managers do not treat all types of failures equally; cost implications and rarity play a role in the level of attention they receive. In particular, our results indicate that, during the earlier stages of development, managers miss an opportunity by not paying enough attention to less salient failures, which have the potential to be quite valuable. As such, we believe that managers should increase their efforts to study less costly failures, since doing so might help their organizations from incurring a more expensive backlash further down the line. We do not suggest that paying more attention to less costly failures should be at the expense of those with higher cost; rather, managers should widen their scope, putting in place processes that allow failures with lesser consequences - which potentially contain important lessons for the future - to be scrutinized more carefully.

Second, failure should still be acknowledged by organizations, but not at the expense of success experience. As our findings show, failure does not always have a greater impact on 
organizational performance than success and, consequently, it should not always be primary focus of attention. Our results show that, in contexts like the biotech industry where success rates are low, success experience positively affects performance. As a result, we suggest that firms put in place systems that maximize the benefits obtained from successful events as a core element of best practice. This is especially important in industries where successes are more frequent and therefore more likely to attract less attention. Processes to analyze success experience should also go beyond the firm's boundaries, as our findings indicate that firms observing success benefit even more than those experiencing it.

Third, managers need to understand that others' failures may indicate problems for their own similar projects. In the biotech industry, managers are well aware of the importance of other related failures, and most firms have well-established processes and protocols in place to scan and analyze related failure events in their environment. Every time a phase III failure takes place in the industry, firms start a process of analysis to try to understand the immediate consequences for their own related projects. Surprisingly, and despite managerial awareness of the importance of others' similar failures, our results show that these efforts are not sufficient enough to improve firms' performances. Therefore, we suggest that managers dedicate greater time to understanding the implications of others' salient failures.

\section{Limitations and Future Research}

Based on the limitations of this study, we can propose a number of recommendations for future research on the topic of failure and success experiences. First, we focused on a specific setting, in the form of a single industry: biotech. Single-industry samples, whilst allowing control for exogenous industry effects, limit generalizability. This is particularly important when the rarity and financial implications of successes and failures vary according to industry conditions. Therefore, it would be advisable to probe generalizability to other sectors, including the development of small-molecule drugs. Similarly, research in other NPD industries with similar rates of failure and success to our sample might also help unearth other nuances not present in our work.

Second, considering prior work, we made several assumptions in order to explain the connection between experience and the probability of future failure. Some of these assumptions 
exist at the micro level, whilst our analysis is conducted at the macro level. For example, we assume that failures and successes cause negative emotions that affect how decision-makers confront future decisions and, accordingly, future performance. This is an important limitation; we believe that future work should look into micro-level factors, such as emotions or decisionmaking processes, and determine how these affect macro-level variables, such as the likelihood of future NPD failure.

The third limitation arises from the fact that we use a limited understanding of related failure and success experiences. In particular, we employ therapeutic areas to determine whether two drug-development projects are related. Despite using very well-established criteria for our chosen industry, this does not exhaust other relevant ways in which two projects might be similar. Specifically, firms could extract relevant information from projects that are similar in biological origin, mode of action, or delivery, even though they might be different in a therapeutic sense. We suggest that other studies use alternative methods to understand the concepts of 'related' and 'unrelated' to see if the findings hold. Changing the industry might also affect how the related/unrelated pair affects performance.

Fourth, this study indicates that the mechanisms employed by firms to extract information from failures and successes are relevant and, in some cases, insufficient to improve organizational performance. Nonetheless, we do not examine how these processes might work. This limitation constitutes an important opportunity for future work. More research on the particular processes that organizations employ to analyze failure and success events is needed. This work could then shed light upon the particular deficiencies that currently exist in the ways that organizations deal with failure and success experiences.

\section{References}

Argote, L., \& Miron-Spektor, E. 2011. Organizational Learning: From Experience to Knowledge, Vol. 22: $1123-1137$.

Argyres, N. S., \& Liebeskind, J. P. 2002. Governance inseparability and the evolution of US biotechnology industry. Journal of Economic Behavior \& Organization, 47(2): 197-219.

Argyris, C., \& Schon, D. A. 1996. Organizational Theory II: Theory, method, and practice. New York: Addison-Wesley.

Audia, P. G., \& Goncalo, J. A. 2007. Past success and creativity over time: A study of inventors in the hard disk drive industry. Management Science, 53(1): 1-15.

Audia, P. G., Locke, E. A., \& Smith, K. G. 2000. The paradox of success: An archival and a laboratory study of strategic persistence following radical environmental change. Academy of Management Journal, 43(5): 837-853.

Barczak, G. 2014. From the Editor. Journal of Product Innovation Management, 31(4): 640-641. 
Baum, J., \& Ingram, P. 1998. Survival Enhancing Learning in the Mahattan Hotel Industry, 1998-1980. Management Science, 44(7): 996-1016.

Baum, J. A. C., \& Dahlin, K. B. 2007. Aspiration Performance and Railroads' Patterns of Learning from Train Wrecks and Crashes. Organization Science, 18(3): 368-385.

Beckman, C. M., \& Haunschild, P. R. 2002. Network Learning: The Effects of Partners' Heterogeneity of Experience on Corporate Acquisitions. Administrative Science Quarterly, 47(1): 92-124.

Bresman, H. 2013. Changing routines: A process model of vicarious group learning in pharmaceutical R\&D. Academy of Management Journal, 56(1): 35-61.

Cannon, M. D., \& Edmondson, A. C. 2001. Confronting failure: antecedents and consequences of shared beliefs about failure in organizational work groups. Journal of Organizational Behavior, 22(2): 161-177.

Carroll, G. R., \& Hannan, M. T. 1995. Organizations in industry : strategy, structure, and selection. Oxford: Oxford University Press.

Castellion, G., \& Markham, S. K. 2013. Perspective: New Product Failure Rates: Influence of Argumentum ad Populum and Self-Interest. Journal of Product Innovation Management, 30(5): 976-979.

Collins, M. 2015. Reducing the Failure Rate Of New Products, Forbes.

Cyert, R. M., \& March, J. 1963. A Behavioral Theory of the Firm. Englewood Cliffs, NJ: Prentice-Hall.

Danzon, P. M., Nicholson, S., \& Pereira, N. S. 2005. Productivity in pharmaceutical-biotechnology R\&D: the role of experience and alliances. Journal of Health Economics, 24(2): 317-339.

Darr, E. D., \& Argote, L. 1995. The Acquisition, Transfer, and Depreciation of Knowledge in Service Organizations: Productivity in Franchises. Management Science, 41(11): 1750-1763.

Deichmann, D., \& Ende, J. v. d. 2013. Rising from failure and learning from success: The role of past experience in radical initiative taking. Organization Science, 25(3): 670-690.

Desai, V. 2014a. Learning through the distribution of failures within an organization: evidence from heart bypass surgery performance. Academy of Management Journal: amj. 2013.0949.

Desai, V. M. 2014b. The impact of media information on issue salience following other organizations' failures. Journal of Management, 40(3): 893-918.

Dillon, R. L., \& Tinsley, C. H. 2008. How near-misses influence decision making under risk: A missed opportunity for learning. Management Science, 54(8): 1425-1440.

DiMasi, J. A., Grabowski, H. G., \& Hansen, R. W. 2016. Innovation in the pharmaceutical industry: new estimates of R\&D costs. Journal of health economics, 47: 20-33.

Disterer, G. 2002. Management of project knowledge and experiences. Journal of Knowledge Management, 6(5): 512-523.

Economist. 2006. When the drugs don't work: Pfizer gives a lesson in risk and reward, Economist. London.

FiercePharma. 2010. Torcetrapib - Pharma's Biggest Flops.

Gardiner, B. 2008. Bank Failure in Second Life Leads to Calls for Regulation. Wired Magazine.

Garzón-Vico, A., Gibbons, P., McNamara, P., \& Rosier, J. 2016. Technological area experience, experience diversity and innovation. Technology Analysis \& Strategic Management, 12(9): 115.

Gavetti, G., Greve, H. R., Levinthal, D. A., \& Ocasio, W. 2012. The behavioral theory of the firm: Assessment and prospects. The academy of management annals, 6(1): 1-40.

Gino, F., \& Pisano, G. P. 2011. Why leaders don't learn from success. Harvard Business Review, 89(4): 68-74.

Gong, Y., Zhang, Y., \& Xia, J. 2017. Do Firms Learn More From Small or Big Successes and Failures? A Test of the Outcome-Based Feedback Learning Perspective. Journal of Management.

Grant, R. M. 1996. Toward a knowledge-based theory of the firm. Strategic Management Journal, 17: 109-122.

Greve, H. R. 2003. Organizational learning from performance feedback: A behavioral perspective on innovation and change: Cambridge University Press. 
Haunschild, P. R., \& Sullivan, B. N. 2002. Learning from Complexity: Effects of Prior Accidents and Incidents on Airlines' Learning. Administrative Science Quarterly, 47(4): 609-643.

Hay, M., Thomas, D. W., Craighead, J. L., Economides, C., \& Rosenthal, J. 2014. Clinical development success rates for investigational drugs. Nature biotechnology, 32(1): 40-51.

Hayward, M. L. A. 2002. When do firms learn from their acquisition experience? Evidence from 1990 to 1995. Strategic Management Journal, 23(1): 21-39.

Hayward, M. L. A., Rindova, V. P., \& Pollock, T. G. 2004. Believing one's own press: The causes and consequences of CEO celebrity. Strategic Management Journal, 25(7): 637-653.

Heckman, J. J. 1979. Sample Selection Bias as a Specification Error. Econometrica, 47(1): 153-161.

Hoang, H., \& Rothaermel, F. T. 2005. The effect of general and partner-specific alliance experience on joint R\&D project performance. Academy of Management Journal, 48(2): 332-345.

Hoang, H., \& Rothaermel, F. T. 2010. Leveraging internal and external experience: exploration, exploitation, and R\&D project performance. Strategic Management Journal, 31(7): 734-758.

Hora, M., \& Klassen, R. D. 2013. Learning from others' misfortune: Factors influencing knowledge acquisition to reduce operational risk. Journal of Operations Management, 31(1/2): 52-61.

Hosmer Jr, D. W., Lemeshow, S., \& Sturdivant, R. X. 2013. Applied logistic regression: John Wiley \& Sons.

Hu, Y., McNamara, P., \& Piaskowska, D. 2016. Project Suspensions and Failures in New Product Development: Returns for Entrepreneurial Firms in Co-Development Alliances. Journal of Product Innovation Management.

Huy, Q. N. 2002. Emotional Balancing of Organizational Continuity and Radical Change: The Contribution of Middle Managers. Administrative Science Quarterly, 47(1): 31-69.

Ingram, P., \& Baum, J. A. C. 1997. Opportunity And Constraint: Organizations' Learning From The Operating And Competitive Experience Of Industries. Strategic Management Journal, 18: 75-98.

Kahneman, D. 2011. Thinking, fast and slow: Macmillan.

Kahneman, D., \& Tversky, A. 2013. Choices, values, and frames, Handbook of the Fundamentals of Financial Decision Making: Part I: 269-278: World Scientific.

KC, D., Staats, B. R., \& Gino, F. 2013. Learning from My Success and from Others' Failure: Evidence from Minimally Invasive Cardiac Surgery. Management Science, 59(11): 2435-2449.

Kiefer, T. 2005. Feeling bad: antecedents and consequences of negative emotions in ongoing change. Journal of Organizational Behavior, 26(8): 875-897.

Kim, J.-Y., Kim, J.-Y., \& Miner, A. S. 2009. Organizational Learning from Extreme Performance Experience: The Impact of Success and Recovery Experience. Organization Science, 20(6): 958978.

Kim, J.-Y. J., \& Miner, A. S. 2007. Vicarious learning from the failures and near-failures of others: Evidence from the U. S. commercial banking industry. Academy of Management Journal, 50(2): 687-714.

Kraaijenbrink, J. 2012. Integrating knowledge and knowledge processes: a critical incident study of product development projects. Journal of product innovation management, 29(6): 1082-1096.

Lampel, J., Shamsie, J., \& Shapira, Z. 2009. Experiencing the Improbable: Rare Events and Organizational Learning. Organization Science, 20(5): 835-845.

Lant, T. K., Milliken, F. J., \& Batra, B. 1992. The role of managerial learning and interpretation in strategic persistence and reorientation: An empirical exploration. Strategic Management Journal, 13(8): 585-608.

Lee, R. P., \& Chen, Q. 2009. The immediate impact of new product introductions on stock price: the role of firm resources and size. Journal of Product Innovation Management, 26(1): 97-107.

Leonard-Barton, D. 1992. Core capabilities and core rigidities: A paradox in managing new product development. Strategic Management Journal, 13(S1): 111-125.

Levinthal, D., \& March, J. G. 1981. A model of adaptive organizational search. Journal of Economic Behavior \&amp; Organization, 2(4): 307-333.

Louis, M. R., \& Sutton, R. I. 1991. Switching Cognitive Gears - from Habits of Mind to Active Thinking. Human Relations, 44(1): 55-76. 
Macher, J. T., \& Boerner, C. 2012. Technological development at the boundaries of the firm: a knowledge-based examination in drug development. Strategic Management Journal, 33(9): 1016-1036.

Macher, J. T., \& Boerner, C. S. 2006. Experience and scale and scope economies: trade-offs and performance in development. Strategic Management Journal, 27(9): 845-865.

Madsen, P. M., \& Desai, V. 2010. Failing to learn? The effects of failure and success on organizational learning in the global orbital launch vehicle industry. Academy of Management Journal, 53(3): 451-476.

Mantere, S., Aula, P., Schildt, H., \& Vaara, E. 2013. Narrative attributions of entrepreneurial failure. Journal of Business Venturing, 28(4): 459-473.

March, J. G. 1991. Exploration and exploitation in organizational learning. Organization Science, 2(1): 71-87.

March, J. G., \& Shapira, Z. 1992. Variable risk preferences and the focus of attention. Psychological Review;Psychological Review, 99(1): 172-183.

Markovitch, D. G., Steckel, J. H., Michaut, A., Philip, D., \& Tracy, W. M. 2015. Behavioral Reasons for New Product Failure: Does Overconfidence Induce Overforecasts? Journal of Product Innovation Management, 32(5): 825-841.

Mayer, K. J., \& Salomon, R. M. 2006. Capabilities, contractual hazards, and governance: Integrating resource-based and transaction cost perspectives. Academy of Management Journal, 49(5): 942-959.

Meschi, P.-X., \& Métais, E. 2013. Do Firms Forget About Their Past Acquisitions? Evidence From French Acquisitions in the United States (1988-2006). Journal of Management, 39(2): 469-495.

Meschi, P. X., \& Métais, E. 2015. Too Big to Learn: The Effects of Major Acquisition Failures on Subsequent Acquisition Divestment. British Journal of Management.

Miller, D. 1994. What Happens After Success: The Perils Of Excellence. Journal of Management Studies, 31(3): 325-358.

Miner, A. S., \& Haunschild, P. R. 1995. Population Level Learning. In B. Staw, \& L. Cummings (Eds.), Research in Organizational Behavior: An Annual Series of Analytical Essays and Critical Reviews/1995: 115-166. Greenwich, CT: Jai Press.

Miner, A. S., Kim, J. Y., Holzinger, I. W., \& Haunschild, P. 1999. Fruits of failure: Organizational failure and population-level learning. Advances in Strategic Management, Vol 16 - 1999, 16: 187-220.

Muehlfeld, K., Rao Sahib, P., \& Van Witteloostuijn, A. 2012. A contextual theory of organizational learning from failures and successes: A study of acquisition completion in the global newspaper industry, 1981-2008. Strategic Management Journal, 33(8): 938-964.

Nelson, R., \& Winter, S. 1982. An evolutionary theory of economic change. Cambridge: The Belknap Press of Harvard University Press.

Nesta, L., \& Saviotti, P. P. 2005. Coherence of the knowledge base and the firm's innovative performance: evidence from the U. S. pharmaceutical industry. The Journal of Industrial Economics, LIII.

Nygren, T. E., Isen, A. M., Taylor, P. J., \& Dulin, J. 1996. The Influence of Positive Affect on the Decision Rule in Risk Situations: Focus on Outcome (and Especially Avoidance of Loss) Rather Than Probability. Organizational Behavior and Human Decision Processes, 66(1): 59-72.

Ocasio, W. 1997. Towards An Attention-Based View Of The Firm Psychology, 1: 403-404.

Olivera, F., \& Argote, L. 1999. Organizational learning and new product development: CORE processes. In J. M. Levine, Leigh L., Thompson, D., Messick, M (Ed.), Shared cognition in organizations: The management of knowledge.: 297-325: Mahwah, NJ, US: Lawrence Erlbaum Associates Publishers.

Paladino, A. 2007. Investigating the drivers of innovation and new product success: a comparison of strategic orientations. Journal of Product Innovation Management, 24(6): 534-553.

Posen, H. E., Lee, J., \& Yi, S. 2013. The power of imperfect imitation. Strategic Management Journal, 34(2): 149-164. 
Scarbrough, H., Robertson, M., \& Swan, J. 2015. Diffusion in the Face of Failure: The Evolution of a Management Innovation. British Journal of Management, 26(3): 365-387.

Shepherd, D. A., \& Cardon, M. S. 2009a. Negative Emotional Reactions to Project Failure and the SelfCompassion to Learn from the Experience. Journal of Management Studies, 46(6): 923-949.

Shepherd, D. A., \& Cardon, M. S. 2009b. Negative Emotional Reactions to Project Failure and the SelfCompassion to Learn from the Experience. Journal of Management Studies, 46(6): 923-949.

Shepherd, D. A., Haynie, J. M., \& Patzelt, H. 2013. Project Failures Arising from Corporate Entrepreneurship: Impact of Multiple Project Failures on Employees' Accumulated Emotions, Learning, and Motivation. Journal of Product Innovation Management, 30(5): 880-895.

Shepherd, D. A., Patzelt, H., Williams, T. A., \& Warnecke, D. 2014. How does project termination impact project team members? rapid termination, 'Creeping Death', and learning from failure. Journal of Management Studies, 51(4): 513-546.

Shepherd, D. A., Patzelt, H., \& Wolfe, M. 2011. Moving Forward From Project Failure: Negative Emotions, Affective Commitment, And Learning From The Experience. Academy of Management Journal, 54(6): 1229-1259.

Simon, H. 1947. Administrative Behavior: A study of Decision-making Processes in Administrative Organizations", Mac Millan: Chicago.

Sitkin, S. B., \& Pablo, A. L. 1992. Reconceptualizing the Determinants of Risk Behavior. The Academy of Management Review, 17(1): 9-38.

Sitkin, S. B., \& Weingart, L. R. 1995. Determinants of risky decision-making behavior: A test of the mediating role of risk perceptions and propensity. Academy of management Journal, 38(6): 1573-1592.

Srinivasan, R., Haunschild, P., \& Grewal, R. 2007. Vicarious Learning in New Product Introductions in the Early Years of a Converging Market. Management Science, 53(1): 16-28.

Su, P., \& McNamara, P. 2012. Exploration and exploitation within and across intra-organisational domains and their reactions to firm-level failure. Technology Analysis \& Strategic Management, 24(2): 129-149.

Talay, M. B., Calantone, R. J., \& Voorhees, C. M. 2014. Coevolutionary dynamics of automotive competition: Product innovation, change, and marketplace survival. Journal of Product Innovation Management, 31(1): 61-78.

Wei, Z., Yi, Y., \& Guo, H. 2014. Organizational learning ambidexterity, strategic flexibility, and new product development. Journal of Product Innovation Management, 31(4): 832-847.

Wry, T., Lounsbury, M., \& Jenni, P. D. 2014. Hybrid vigor: securing venture capital by spanning categories in nanotechnology Academy of Management Journal, 57(5): 1309-1333.

Yang, J. Y., Li, J., \& Delios, A. 2015. Will a second mouse get the cheese? Learning from early entrants' failures in a foreign market. Organization Science, 26(3): 908-922. 
Table 1. Descriptive Statistics

\begin{tabular}{|c|c|c|c|c|c|c|c|c|c|}
\hline & Mean & Std. Dv. & Min. & Max. & 1 & 2 & 3 & 4 & 5 \\
\hline 1. Ceased & 0.84 & 0.36 & 0.00 & 1.00 & 1.00 & & & & \\
\hline 2. R\&D Alliance & 0.41 & 0.49 & 0.00 & 1.00 & -0.02 & 1.00 & & & \\
\hline 3. Year & 2008 & 4 & 2000 & 2015 & 0.00 & $-0.06^{* *}$ & 1.00 & & \\
\hline 4. Organization's Role & 0.76 & 0.43 & 0.00 & 1.00 & $0.05^{*}$ & $-0.67 * * *$ & $0.05^{* *}$ & 1.00 & \\
\hline 5. Percentage Failed & 55.32 & 44.05 & 0.00 & 100.00 & $0.20 * * *$ & $0.08 * * *$ & $0.04 *$ & $-0.06 * *$ & 1.00 \\
\hline 6. Therapeutic area experience & 5.43 & 10.08 & 0.00 & 57.00 & $-0.10^{* * *}$ & $-0.10^{* * *}$ & -0.00 & $0.06^{* * *}$ & $0.13^{* * *}$ \\
\hline 7. Rare Disease & 0.04 & 0.19 & 0.00 & 1.00 & 0.01 & 0.01 & -0.01 & -0.01 & 0.01 \\
\hline 8. Therapeutic Area Risk & 81.19 & 24.93 & 0.00 & 100.00 & $0.41^{* * *}$ & $0.07^{* * *}$ & 0.03 & -0.03 & $0.19^{* * *}$ \\
\hline 9. Biological Origin Risk & 84.14 & 16.02 & 0.00 & 100.00 & $0.29 * * *$ & $0.04 *$ & -0.02 & -0.00 & $0.05^{*}$ \\
\hline 10. R\&D Investment (in million \$) & 1325 & 2331 & 0.43 & 9877.73 & 0.01 & $0.06^{* *}$ & $0.08^{* * *}$ & $-0.09 * * *$ & $0.33^{* * *}$ \\
\hline $\begin{array}{l}\text { 11. First-Hand Success Experience } \\
\text { (Age Square Disc.) }\end{array}$ & 0.03 & 0.17 & 0.00 & 1.55 & $-0.34 * * *$ & $-0.04 *$ & $0.07 * * *$ & 0.00 & $-0.14 * * *$ \\
\hline $\begin{array}{l}\text { 12. First-Hand Early-Stage Failure Experience } \\
\text { (Age Disc.) }\end{array}$ & 0.04 & 0.17 & 0.00 & 2.28 & $0.07 * * *$ & $-0.06 * *$ & 0.02 & $0.05^{* *}$ & $0.18^{* * *}$ \\
\hline $\begin{array}{l}\text { 13. First-Hand Medium-Stage Failure Experience } \\
\text { (Age Disc.) }\end{array}$ & 0.02 & 0.13 & 0.00 & 1.50 & $0.05^{* *}$ & -0.03 & -0.01 & 0.02 & $0.15^{* * *}$ \\
\hline $\begin{array}{l}\text { 14. First-Hand Late-stage Failure Experience } \\
\text { (No Disc.) }\end{array}$ & 2.35 & 4.35 & 0.00 & 21.00 & 0.03 & -0.02 & $0.07 * * *$ & -0.00 & $0.35^{* * *}$ \\
\hline $\begin{array}{l}\text { 15. Others' Related Success Experience } \\
\text { (Age Disc.) }\end{array}$ & 0.21 & 0.77 & 0.00 & 10.51 & $-0.25^{* * *}$ & $0.05^{*}$ & -0.03 & $-0.07 * * *$ & $-0.05^{*}$ \\
\hline $\begin{array}{l}\text { 16. Others' Related Late-stage Failure Experience } \\
\text { (Age Square Root Disc) }\end{array}$ & 98.87 & 86.57 & 0.00 & 268.00 & $0.27 * * *$ & 0.03 & $0.16^{* * *}$ & -0.01 & $0.17^{* * *}$ \\
\hline
\end{tabular}


Table 1. Descriptive Statistics (continued)

\begin{tabular}{|c|c|c|c|c|c|c|c|c|c|c|c|}
\hline & 6 & 7 & 8 & 9 & 10 & 11 & 12 & 13 & 14 & 15 & 16 \\
\hline 6. Therapeutic Area Experience & 1.00 & & & & & & & & & & \\
\hline 7. Rare Disease & -0.04 & 1.00 & & & & & & & & & \\
\hline 8. Therapeutic Area Risk & -0.03 & 0.03 & 1.00 & & & & & & & & \\
\hline 9. Biological Origin Risk & -0.00 & $0.05 * *$ & $0.38^{* * *}$ & 1.00 & & & & & & & \\
\hline 10. R\&D Investment (In Million \$) & 0.02 & 0.00 & 0.03 & $-0.12 * * *$ & 1.00 & & & & & & \\
\hline $\begin{array}{l}\text { 11. First-Hand Success Experience } \\
\text { (Age Square Disc.) }\end{array}$ & $0.48^{* * *}$ & -0.02 & $-0.20 * * *$ & $-0.09 * * *$ & $-0.05^{* *}$ & 1.00 & & & & & \\
\hline $\begin{array}{l}\text { 12. First-Hand Early-Stage Failure Experience } \\
\text { (Age Disc.) }\end{array}$ & $0.40^{* * *}$ & -0.02 & $0.04 *$ & 0.00 & $0.09 * * *$ & -0.03 & 1.00 & & & & \\
\hline $\begin{array}{l}\text { 13. First-Hand Medium-Stage Failure Experience } \\
\text { (Age Disc.) }\end{array}$ & $0.31 * * *$ & -0.01 & $0.05^{*}$ & -0.00 & $0.10^{* * *}$ & -0.03 & $0.04 *$ & 1.00 & & & \\
\hline $\begin{array}{l}\text { 14. First-Hand Late-Stage Failure Experience (No } \\
\text { Disc.) }\end{array}$ & 0.02 & 0.00 & 0.00 & $-0.10 * * *$ & $0.66^{* * *}$ & $-0.06^{* *}$ & $0.06^{* * *}$ & $0.09^{* * *}$ & 1.00 & & \\
\hline $\begin{array}{l}\text { 15. Others' Related Success Experience } \\
\text { (Age Disc.) }\end{array}$ & $0.31 * * *$ & -0.03 & $-0.16^{* * *}$ & $-0.18 * * *$ & -0.01 & $0.58^{* * *}$ & -0.01 & -0.01 & 0.00 & 1.00 & \\
\hline $\begin{array}{l}\text { 16. Others' Related Late-stage Failure Experience } \\
\text { (Ages Square Root Disc) }\end{array}$ & $0.04 *$ & 0.01 & $0.51^{* * *}$ & $0.27^{* * *}$ & $0.06^{* * *}$ & $-0.14 * * *$ & $0.04 *$ & $0.08^{* * *}$ & $0.05^{* *}$ & $-0.09 * * *$ & 1.00 \\
\hline
\end{tabular}


Table 2. Logistic Models Predicting Drug Failure

\begin{tabular}{|c|c|c|c|c|c|c|c|c|c|c|}
\hline Variable & Model 1 & Model 2 & Model 3 & Model 4 & Model 5 & Model 6 & Model 7 & Model 8 & Model 9 & Model 10 \\
\hline R\&D Alliance & $\begin{array}{l}-0.53 \\
(0.29)\end{array}$ & $\begin{array}{l}-0.50 \\
(0.29)\end{array}$ & $\begin{array}{l}-0.50 \\
(0.29)\end{array}$ & $\begin{array}{l}-0.53 \\
(0.29)\end{array}$ & $\begin{array}{l}-0.52 \\
(0.28)\end{array}$ & $\begin{array}{l}-0.48 \\
(0.29)\end{array}$ & $\begin{array}{l}-0.52 \\
(0.29)\end{array}$ & $\begin{array}{l}-0.52 \\
(0.29)\end{array}$ & $\begin{array}{l}-0.49 \\
(0.29)\end{array}$ & $\begin{array}{l}-0.49 \\
(0.29)\end{array}$ \\
\hline Year & $\begin{array}{l}0.20^{* * *} \\
(0.03)\end{array}$ & $\begin{array}{l}0.19^{* * *} \\
(0.03)\end{array}$ & $\begin{array}{l}0.20^{* * *} \\
(0.03)\end{array}$ & $\begin{array}{l}0.24^{* * *} \\
(0.04)\end{array}$ & $\begin{array}{l}0.19^{* * *} \\
(0.03)\end{array}$ & $\begin{array}{l}0.24^{* * *} \\
(0.04)\end{array}$ & $\begin{array}{l}0.19^{* * *} \\
(0.04)\end{array}$ & $\begin{array}{l}0.23^{* * *} \\
(0.04)\end{array}$ & $\begin{array}{l}0.20^{* * *} \\
(0.03)\end{array}$ & $\begin{array}{c}0.20^{* * *} \\
(0.03)\end{array}$ \\
\hline Organization's Role & $\begin{array}{c}-0.09 \\
(0.28)\end{array}$ & $\begin{array}{c}-0.08 \\
(0.28)\end{array}$ & $\begin{array}{c}-0.08 \\
(0.28)\end{array}$ & $\begin{array}{c}-0.10 \\
(0.28)\end{array}$ & $\begin{array}{c}-0.15 \\
(0.28)\end{array}$ & $\begin{array}{c}-0.13 \\
(0.28)\end{array}$ & $\begin{array}{c}-0.12 \\
(0.28)\end{array}$ & $\begin{array}{c}-0.13 \\
(0.28)\end{array}$ & $\begin{array}{c}-0.16 \\
(0.28)\end{array}$ & $\begin{array}{c}-0.17 \\
(0.28)\end{array}$ \\
\hline Percentage Failed & $\begin{array}{c}-0.03^{* * * *} \\
(0.01)\end{array}$ & $\begin{array}{c}-0.03^{* * * *} \\
(0.01)\end{array}$ & $\begin{array}{c}-0.03^{* * * *} \\
(0.01)\end{array}$ & $\begin{array}{c}-0.03^{* * * *} \\
(0.01)\end{array}$ & $\begin{array}{c}-0.03^{* * * *} \\
(0.01)\end{array}$ & $\begin{array}{c}-0.03^{* * * *} \\
(0.01)\end{array}$ & $\begin{array}{c}-0.03^{* * * *} \\
(0.01)\end{array}$ & $\begin{array}{c}-0.03^{* * *} \\
(0.01)\end{array}$ & $\begin{array}{c}-0.03^{* * * *} \\
(0.01)\end{array}$ & $\begin{array}{c}-0.03^{* * * *} \\
(0.01)\end{array}$ \\
\hline Therapeutic Area Experience & $\begin{array}{l}-0.07 \\
(0.33)\end{array}$ & $\begin{array}{l}-0.24 \\
(0.34)\end{array}$ & $\begin{array}{l}-0.20 \\
(0.34)\end{array}$ & $\begin{array}{l}-0.06 \\
(0.33)\end{array}$ & $\begin{array}{c}0.83 \\
(0.56)\end{array}$ & $\begin{array}{c}0.37 \\
(0.58)\end{array}$ & $\begin{array}{l}-0.13 \\
(0.34)\end{array}$ & $\begin{array}{l}-0.12 \\
(0.34)\end{array}$ & $\begin{array}{c}0.53 \\
(0.44)\end{array}$ & $\begin{array}{c}0.81 \\
(0.57)\end{array}$ \\
\hline Rare Disease & $\begin{array}{c}-0.56 \\
(0.48)\end{array}$ & $\begin{array}{l}-0.54 \\
(0.47)\end{array}$ & $\begin{array}{l}-0.55 \\
(0.48)\end{array}$ & $\begin{array}{c}-0.53 \\
(0.48)\end{array}$ & $\begin{array}{c}-0.53 \\
(0.47)\end{array}$ & $\begin{array}{c}-0.49 \\
(0.48)\end{array}$ & $\begin{array}{c}-0.47 \\
(0.48)\end{array}$ & $\begin{array}{c}-0.44 \\
(0.48)\end{array}$ & $\begin{array}{c}-0.56 \\
(0.48)\end{array}$ & $\begin{array}{c}-0.55 \\
(0.48)\end{array}$ \\
\hline Therapeutic Area Risk & $\begin{array}{c}0.04^{* * *} \\
(0.01)\end{array}$ & $\begin{array}{c}0.04^{* * *} \\
(0.01)\end{array}$ & $\begin{array}{c}0.04^{* * *} \\
(0.01)\end{array}$ & $\begin{array}{c}0.04^{* * *} \\
(0.01)\end{array}$ & $\begin{array}{c}0.04^{* * *} \\
(0.01)\end{array}$ & $\begin{array}{c}0.04^{* * *} \\
(0.01)\end{array}$ & $\begin{array}{c}0.03^{* * *} \\
(0.01)\end{array}$ & $\begin{array}{c}0.03^{* * *} \\
(0.01)\end{array}$ & $\begin{array}{c}0.03^{* * *} \\
(0.01)\end{array}$ & $\begin{array}{c}0.03^{* * *} \\
(0.01)\end{array}$ \\
\hline Biological Origin Risk & $\begin{array}{c}0.05^{* * *} \\
(0.01)\end{array}$ & $\begin{array}{c}0.05^{* * *} \\
(0.01)\end{array}$ & $\begin{array}{c}0.05^{* * *} \\
(0.01)\end{array}$ & $\begin{array}{c}0.05^{* * *} \\
(0.01)\end{array}$ & $\begin{array}{c}0.05^{* * *} \\
(0.01)\end{array}$ & $\begin{array}{c}0.05^{* * *} \\
(0.01)\end{array}$ & $\begin{array}{c}0.05^{* * *} \\
(0.01)\end{array}$ & $\begin{array}{c}0.05^{* * *} \\
(0.01)\end{array}$ & $\begin{array}{c}0.05^{* * *} \\
(0.01)\end{array}$ & $\begin{array}{c}0.05^{* * *} \\
(0.01)\end{array}$ \\
\hline$R \& D$ Investment & $\begin{array}{l}-0.00^{* *} \\
(0.00)\end{array}$ & $\begin{array}{l}-0.00^{* *} \\
(0.00)\end{array}$ & $\begin{array}{l}-0.00^{* *} \\
(0.00)\end{array}$ & $\begin{array}{l}-0.00 \\
(0.00)\end{array}$ & $\begin{array}{l}-0.00^{* *} \\
(0.00)\end{array}$ & $\begin{array}{l}-0.00^{*} \\
(0.00)\end{array}$ & $\begin{array}{l}-0.00^{* * *} \\
(0.00)\end{array}$ & $\begin{array}{l}-0.00 \\
(0.00)\end{array}$ & $\begin{array}{l}-0.00^{* *} \\
(0.00)\end{array}$ & $\begin{array}{l}-0.00^{* *} \\
(0.00)\end{array}$ \\
\hline Inverse Mill's Ratio & $\begin{array}{l}-2.47^{*} \\
(1.07)\end{array}$ & $\begin{array}{l}-2.46^{*} \\
(1.07)\end{array}$ & $\begin{array}{l}-2.46^{*} \\
(1.07)\end{array}$ & $\begin{array}{l}-2.15 \\
(1.10)\end{array}$ & $\begin{array}{l}-2.38^{*} \\
(1.07)\end{array}$ & $\begin{array}{l}-2.05 \\
(1.09)\end{array}$ & $\begin{array}{l}-2.19^{*} \\
(1.07)\end{array}$ & $\begin{array}{l}-1.83 \\
(1.10)\end{array}$ & $\begin{array}{l}-2.01 \\
(1.09)\end{array}$ & $\begin{array}{l}-2.02 \\
(1.08)\end{array}$ \\
\hline $\begin{array}{l}\text { First-hand early-stage failure experience (Age } \\
\text { Disc.) }\end{array}$ & & $\begin{array}{c}3.02 \\
(1.93)\end{array}$ & & & & $\begin{array}{c}2.77 \\
(2.05)\end{array}$ & & & & \\
\hline $\begin{array}{l}\text { First-hand medium-stage failure experience } \\
\text { (Age Disc.) }\end{array}$ & & & $\begin{array}{c}2.23 \\
(1.60)\end{array}$ & & & $\begin{array}{c}1.80 \\
(1.68)\end{array}$ & & & & \\
\hline $\begin{array}{l}\text { First-hand late-stage failure experience (No } \\
\text { Disc.) }\end{array}$ & & & & $\begin{array}{l}-0.11^{*} \\
(0.65)\end{array}$ & & $\begin{array}{l}-0.11^{*} \\
(0.65)\end{array}$ & & $-0.11^{*}$ & & \\
\hline $\begin{array}{l}\text { First-hand success experience (Age Square } \\
\text { Disc.) }\end{array}$ & & & & & $\begin{array}{l}-2.17^{* *} \\
(0.83)\end{array}$ & $\begin{array}{l}-1.68^{*} \\
(0.83)\end{array}$ & & & & $\begin{array}{l}-0.91 \\
(0.95)\end{array}$ \\
\hline $\begin{array}{l}\text { Others' related late-stage failure experience } \\
\text { (Age Square Root Disc) }\end{array}$ & & & & & & & $\begin{array}{l}0.12^{*} \\
(0.06)\end{array}$ & $\begin{array}{l}0.12^{*} \\
(0.06)\end{array}$ & & \\
\hline Others' related success experience (Age Disc.) & & & & & & & $(0.06)$ & $(0.00)$ & $\begin{array}{l}-0.67^{* * *} \\
(0.08)\end{array}$ & $\begin{array}{c}-0.63^{* *} \\
(0.08)\end{array}$ \\
\hline Wald Chi Square & 217.18 & 221.22 & 220.45 & 225.93 & 222.66 & 238.17 & 224.77 & 230.16 & 235.09 & 235.11 \\
\hline Log Likelihood & -334.06 & -332.04 & -332.43 & -329.69 & -331.32 & -323.57 & -330.26 & -327.57 & -325.11 & -325.09 \\
\hline$N$ & 1145 & 1145 & 1145 & 1145 & 1145 & 1145 & 1145 & 1145 & 1145 & 1145 \\
\hline Clusters & 79 & 79 & 79 & 79 & 79 & 79 & 79 & 79 & 79 & 79 \\
\hline
\end{tabular}

Positive coefficients indicate that increases in the value of independent and control variables increase the probability of drug development failure and vice versa. ${ }^{*} P<.05$, ${ }^{* *} P<.01,{ }^{* * *} P<.001$. 
Figure 1: Hypotheses comparing different type of experience impact on the likelihood of future failure

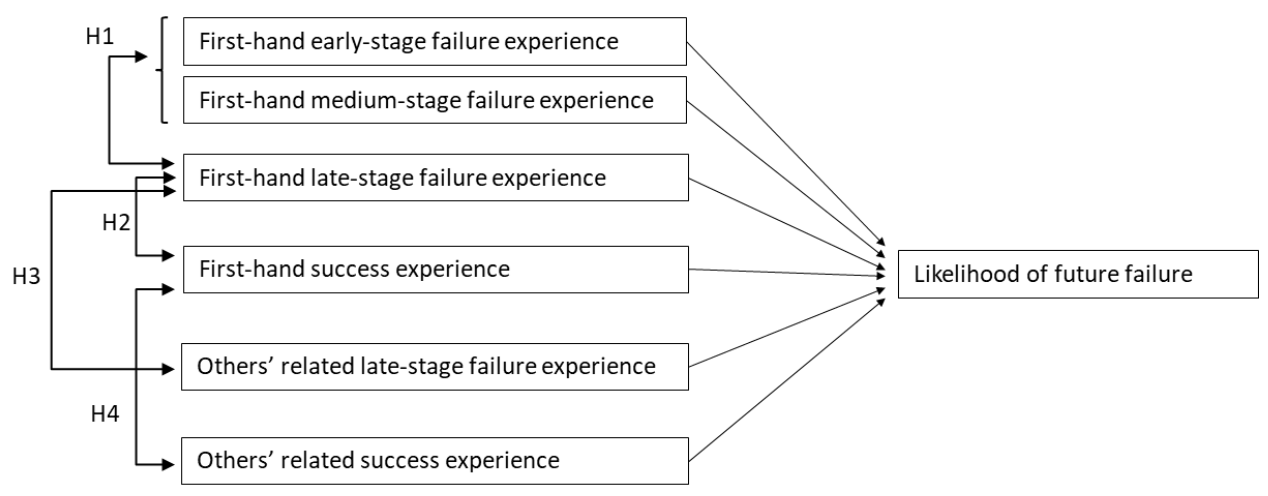

Figure 2. Effect of First-Hand Late-Stage Failure Experience on Project Failure.

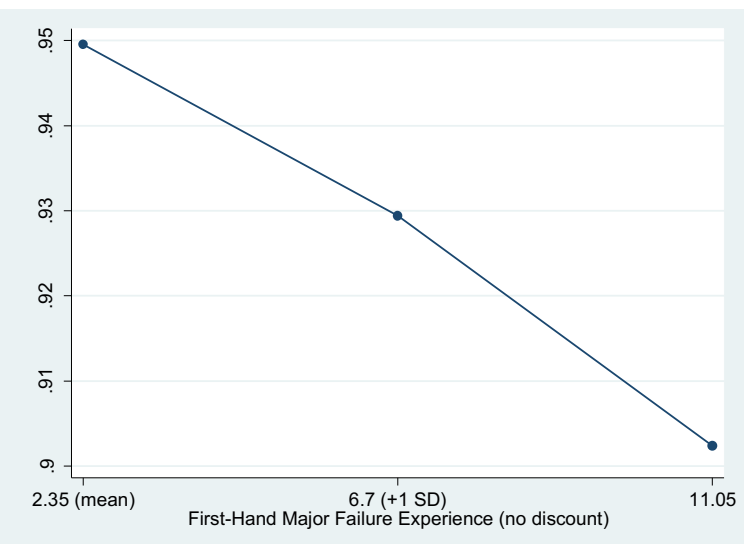


Figure 3. Effect of First-Hand Success Experience on Project Failure.

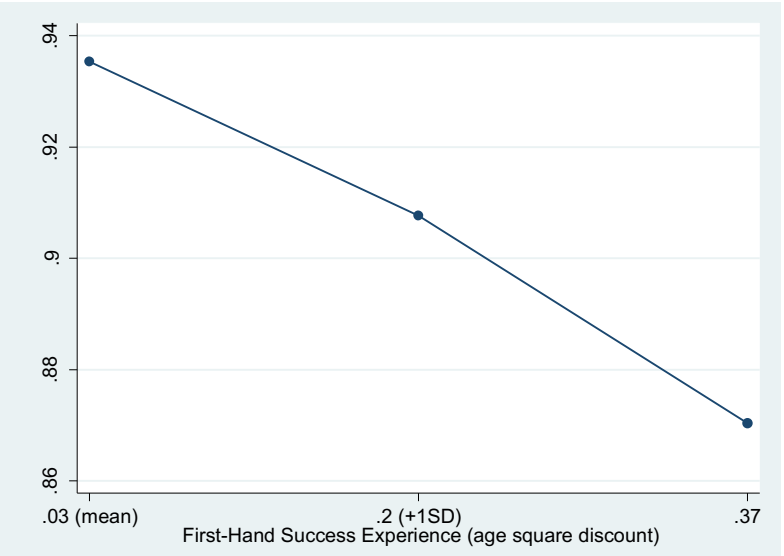

Figure 4. Effect of Others' Related Late-stage Failure Experience on Project Failure.

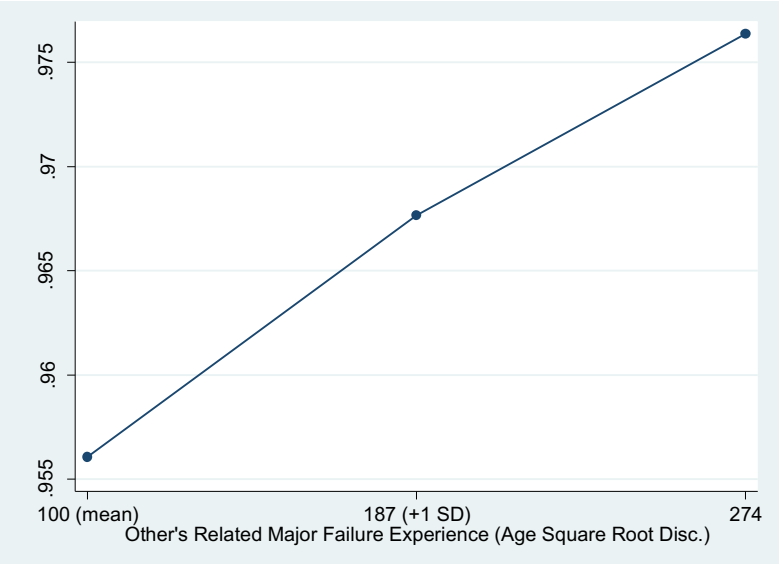


Figure 5. Effect of Others' Related Success Experience on Project Failure.

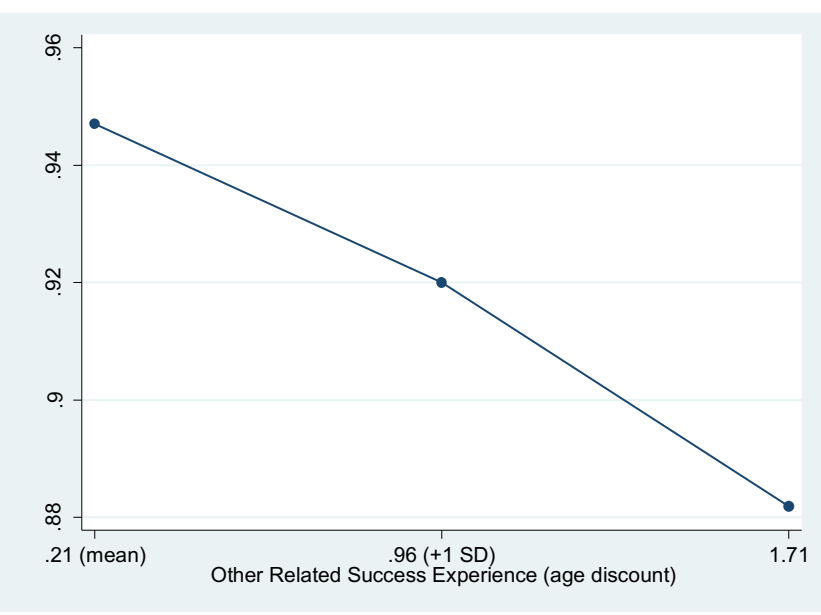


Table 3. Robustness Test: Probit Models Predicting Drug Failure

\begin{tabular}{|c|c|c|c|c|c|c|c|c|c|c|}
\hline Variable & Model 1 & Model 2 & Model 3 & Model 4 & Model 5 & Model 6 & Model 7 & Model 8 & Model 9 & Model 10 \\
\hline R\&D Alliance & -0.25 & -0.23 & -0.24 & $-0.26^{*}$ & $-0.25^{*}$ & -0.24 & -0.25 & $-0.26^{*}$ & $-0.26^{*}$ & $-0.27 *$ \\
\hline Year & $0.04 *$ & $0.03 *$ & $0.04 *$ & $0.05 * *$ & 0.02 & $0.03 *$ & $0.03^{*}$ & 0.03 & $0.04 *$ & $0.05^{* *}$ \\
\hline Organization's Role & 0.04 & 0.05 & 0.04 & 0.04 & 0.03 & 0.04 & 0.02 & 0.03 & 0.03 & 0.03 \\
\hline Percentage Failed & 0.00 & 0.00 & 0.00 & 0.00 & 0.00 & 0.00 & 0.00 & 0.00 & 0.00 & 0.00 \\
\hline Therapeutic area experience & 0.00 & 0.00 & 0.00 & 0.01 & 0.00 & 0.01 & 0.00 & 0.00 & -0.01 & 0.00 \\
\hline Rare Disease & -0.16 & -0.14 & -0.15 & -0.14 & -0.16 & -0.12 & -0.18 & -0.18 & -0.17 & -0.15 \\
\hline Therapeutic Area Risk & $0.02 * * *$ & $0.02 * * *$ & $0.02 * * *$ & $0.02^{* * *}$ & $0.02^{* * *}$ & $0.02^{* * *}$ & $0.02 * * *$ & $0.02^{* * *}$ & $0.02 * * *$ & $0.02 * * *$ \\
\hline Biological Origin Risk & $0.02 * * *$ & $0.02 * * *$ & $0.02 * * *$ & $0.02 * * *$ & $0.02 * * *$ & $0.02 * * *$ & $0.02 * * *$ & $0.02^{* * *}$ & $0.02^{* * *}$ & $0.02 * * *$ \\
\hline R\&D Investment & 0.00 & 0.00 & 0.00 & 0.00 & 0.00 & 0.00 & 0.00 & 0.00 & 0.00 & 0.00 \\
\hline First-hand early-stage failure experience (Age Disc.) & & 1.63 & & & & 1.74 & & & & \\
\hline First-hand medium-stage failure experience (Age Disc.) & & & 1.32 & & & 1.2 & & & & \\
\hline First-hand late-stage failure experience (No Disc.) & & & & $-0.06^{*}$ & & $-0.06^{*}$ & & & & -0.04 \\
\hline First-hand success experience (Age Square Disc.) & & & & & $-1.59 * * *$ & $-1.59 * * *$ & & $-1.21 * * *$ & & \\
\hline Others' related success experience (Age Disc.) & & & & & & & $-0.42 * * *$ & $-0.32 * *$ & & \\
\hline $\begin{array}{l}\text { Others' related late-stage failure experience (Age Square Root } \\
\text { Disc) }\end{array}$ & & & & & & & & & $0.08 * *$ & $0.07^{*}$ \\
\hline Wald Chi Square & 226.99 & 249.93 & 226.94 & 226.90 & 226.02 & 247.11 & 226.75 & 245.80 & 228.81 & 228.07 \\
\hline Log Likelihood & -831.94 & -817.30 & -828.27 & -829.88 & -829.32 & -809.27 & -818.71 & -812.44 & -827.74 & -826.36 \\
\hline$N$ & 2750 & 2750 & 2750 & 2750 & 2750 & 2750 & 2750 & 2750 & 2750 & 2750 \\
\hline Clusters & 848 & 848 & 848 & 848 & 848 & 848 & 848 & 848 & 848 & 848 \\
\hline
\end{tabular}

Positive coefficients indicate that increases in the value of independent and control variables increase the probability of drug development failure and vice versa. $*_{P}<.05,{ }^{*} *_{P}<.01, * * * P<.001$. 